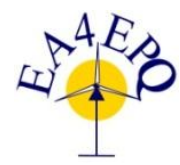

International Conference on Renewable Energies and Power Quality (ICREPQ'13) Bilbao (Spain), 20 $0^{\text {th }}$ to $22^{\text {th }}$ March, 2013

Renewable Energy and Pourer Qualily. Fournal (RE\&PQJ)

ISSN 2172-038 X, No.11, March 2013

\title{
A Study of Cycle Analysis and Turbine Design for Obtaining Small-Scaled Power from the Organic Rankine Cycle Using R245fa
}

\author{
S. $\mathrm{Cho}^{1}$, C. $\mathrm{Cho}^{2}$ and C. $\mathrm{Kim}^{3}$ \\ ${ }^{1}$ Department of Aerospace and System Engineering, Gyeongsang National University \\ Jinju, Gyeongam, 660-701, S. Korea \\ Phone/Fax number:+8255 772 1644/1580, e-mail: sycho@gnu.ac.kr \\ ${ }^{2}$ R\&D Center, Sun-Tech, Sooncheon, Jeonnam, 540-320, S. Korea \\ Phone/Fax number:+8261 723 7272/722 3388, e-mail: air0427@empal.com \\ ${ }^{3}$ Dept. of Mechanical Engr., Changwon National University, Gyeongam, 641-773, S. Korea \\ Phone/Fax number:+8255 213 3604/3607, e-mail: kimcs@changwon.ac.kr
}

\begin{abstract}
The organic Rankine cycle (ORC) has been widely applied to convert the renewable energy to the electric power. Some previous studies focused to find what kind of refrigerant would be a best working fluid for the ORC. In this study, R245fa was chosen as the working fluid, and the cycle analysis was conducted when the small scaled output power less than $30 \mathrm{~kW}$ was required. In addition, properties of the working fluid on the cycle were predicted when the turbine output power was controlled by the mass flowrate. The configuration of the turbine was the radial-type turbine and the supersonic nozzles were applied as stator. So, the turbine was operated in partial admission. The turbine efficiency as well as the optimum velocity ratio was considered in the cycle analysis with the low partial admission rate. The computed results show that the partial admission rate was more important factor on the system efficiency than the temperature at the evaporator.
\end{abstract}

\section{Key words}

Organic Rankine Cycle, Cycle Analysis, Energy Recovery, Radial Turbine, Partial Admission

\section{Introduction}

Lots of researches about renewable energy have been conducting as being depleted the resource. Most of researches focus obtaining useful energy efficiently from wind power, solar energy, wave power, or geothermal energy etc.,. The solar energy is usually converted to the electric power through the solar cell or to the thermal energy through the solar collector. The wind power, the geothermal energy and the wave power are transformed to the electric power using turbine. Wasted thermal energy as well as heat source from the solar or geothermal energy can be converted to the electric power by the steam turbine or the organic Rankine cycle (ORC). The ORC has merits because its operating fluid (refrigerant) has low evaporation temperature and high condensing temperature compared to the steam. Therefore, the ORC can be applied even though the temperature of heat source is low.

The refrigerant as the operating fluid of ORC does not deplete the ozone layer. In addition, it has low global warming potential, inflammable, highly efficient, and nontoxic properties. For these reasons, the natural refrigerant of carbon dioxide can be adopted. However, it has disadvantage in cost. So, refrigerants altered from the chlorofluorocarbons (CFC) or hydrofluorocarbons (HFC) refrigerant are usually adopted. Cong [1] used R123 and isobutene for the ORC. The optimum turbine inlet pressure and temperature in the cycle was studied when the solar energy was applied as heat source. Liu et al. [2] conducted the cycle analysis of ORC with the operating fluids of water, ethanol, benzene, or toluene etc. for recovering the waste thermal energy. Hung et al. [3] studied the cycle analysis of ORC with seven different refrigerants. Additionally, Hung et al. [4] conducted the cycle analysis of ORC with eleven different refrigerants for obtaining useful power from the low temperature heat source such as the solar energy or ocean temperature difference energy. Gang et al. [5] applied the regenerative cycle to the ORC. The efficiency of the ORC was improved to $8.6 \%$ from $4.9 \%$.

Millimeter scaled turbine for ORC was tested by Yamamoto et al. [6]. Its diameter was $30 \mathrm{~mm}$ and the output power of $150 \mathrm{~W}$ was obtained at 20,0000RPM. The maximum efficiency of the ORC was $1.25 \%$. Welch et al. [7] adopted Euler turbine operating at two-phase. The operating fluid of low surface tension showed better system efficiency. Kang [8] conducted the ORC experiment using the radial-type turbine of $30 \mathrm{~kW}$ class with R245fa refrigerant. Declaye et al. [9] adopted the scroll expander for ORC with R245fa and HEF7000 refrigerants. 
In this study, the cycle analysis of ORC was conducted while the amount of heat source was varied. Therefore, off design point operation as well as design point operation was studied. For varying the amount of heat source, the turbine power was controlled by the mass flowrate. For this, the turbine was operated at partial admission. Therefore, the efficiency of turbine and the optimum velocity ratio were considered for the partial admitted turbine and the various system efficiencies of ORC were obtained.

\section{Cycle Analysis}

Fig. 1 shows the schematic diagram of the ORC system. The heat source is available from the wasted heat, the solar energy, or the geothermal energy etc. even though its temperature is near $100^{\circ} \mathrm{C}$. In this study, R245fa refrigerant was adopted as the operating fluid. The evaporated refrigerant operates the turbine, and then changes to low-pressure/low-temperature state at the exit of turbine. This refrigerant is liquefied at the condenser, and then it is pressurized by the pump. Through this process, the ORC system obtains the power on the generator connected to the turbine.

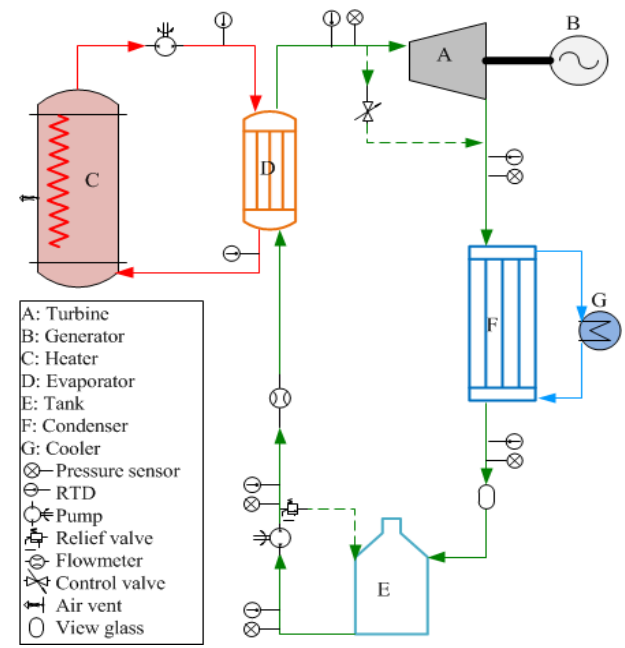

Fig. 1 Schematic diagram of an organic Rankine system

Each location in the cycle of ORC is marked as the number in the Fig. 2. The evaporated refrigerant is superheated by $3^{\circ} \mathrm{C}$ to avoid liquefying within the turbine. So, the total temperature $\left(T_{t 1}\right)$ at the turbine inlet can be decided as Eq. (1). The evaporation temperature $\left(T_{\text {eva }}\right)$ is the saturated temperature which is depended on the turbine inlet pressure $\left(P_{t 1}\right)$.

$$
\begin{aligned}
& T_{t 1}=T_{\text {eva }}+3^{o} C \\
& T_{\text {eva }}=f\left(P_{t 1}\right)
\end{aligned}
$$

The total enthalpy $\left(h_{t 1}\right)$ at turbine inlet can be obtained from the total pressure and total temperature, and the static enthalpy $(h)$ is calculated with the velocity $\left(C_{1}\right)$ at the duct. In this calculation, the cycle analysis was conducted using the libraries of NIST Refprop [10].

In this study, the turbine power ( $\Pi$ ) was decided to $30 \mathrm{~kW}$ based on the available heat source. However, the turbine could be operated at the condition of output power less than $30 \mathrm{~kW}$ when the amount of available heat source is reduced. So, the configuration of the turbine was designed based on the $30 \mathrm{~kW}$ output power. For the less power, the turbine is operated at off-design point. Even though the turbine is millimeter scale class, the turbine is operated in partial admission due to low mass flowrate. Therefore, the turbine should be designed to impulse-type turbine which works well in partial admission. In the impulse-type turbine, the expansion of the refrigerant occurs at the stator, and then this expanded power is absorbed at the rotor. Hence, the stator was designed to the expansion nozzle.

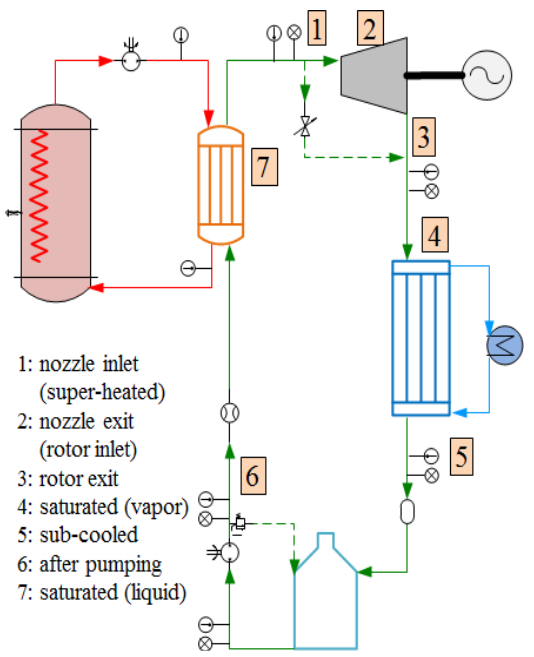

Fig. 2 Locations for organic Rankine cycle analysis

The total pressure $\left(P_{t 2}\right)$ and total enthalpy $\left(h_{t 2}\right)$ at the nozzle exit can be the same values at the turbine inlet when the pressure loss within the nozzle is supposed to be infinitesimal. If the velocity at the nozzle exit is bigger, the rotor size can be smaller. Hence, the velocity $\left(C_{2}\right)$ at the nozzle exit was decided to Mach number of 1.4. In order to get this velocity, the static pressure $\left(P_{2}\right)$ at the nozzle exit was iteratively calculated until the total pressure $\left(P_{t 2}\right)$ and total enthalpy $\left(h_{t 2}\right)$ at the nozzle exit were satisfied. The efficiency of the nozzle was supposed to $95 \%$.

$$
\begin{aligned}
& h_{2}=f\left(P_{2}, s_{2}\right) \\
& h_{t 2}=h_{2}+\frac{C_{2}^{2}}{2 \eta_{N}}
\end{aligned}
$$

where $s$ in Eq. (2) is the entropy. The nozzle shape was adopted as circular-type. The exit diameter $\left(d_{2}\right)$ of the nozzle can be decided in the basis of the rotor configuration. The mass flowrate $\left(\dot{m}_{n}\right)$ on the one nozzle is obtained as Eq. (3).

$$
\dot{m}_{n}=\rho_{2} C_{2} \frac{\pi d_{2}^{2}}{4}
$$

where $\rho$ in Eq. (3) is the density. The rotational speed of the rotor can be decided based on the maximum efficiency operating condition from the relationship of the spouting velocity $\left(C_{j}\right)$ at the nozzle and the circumferential velocity $(U)$. 
Figure 3 shows the velocity ratio which revealed the maximum efficiency operating conditions [11-14] when the turbine operated in partial admission. It shows the characteristics such that the optimum velocity ratio is reduced when the partial admission rate is decreased. In this study, the circumferential velocity of the turbine was chosen based on the optimum velocity ratio. The output power of the turbine is evaluated based on the circumferential velocity, the absolute velocity $\left(C_{\theta 2}\right)$ along the circumferential direction and the turbine efficiency $\left(\eta_{t-t}\right)$. The turbine efficiency was applied the efficiency which was obtained at the optimum velocity ratio, as shown in Fig. 4.

$$
\begin{aligned}
& \Pi=\dot{m} \Delta h_{t} \eta_{t-t} \\
& \Delta h_{t}=C_{\theta 2} U_{2}-C_{\theta 3} U_{3}
\end{aligned}
$$

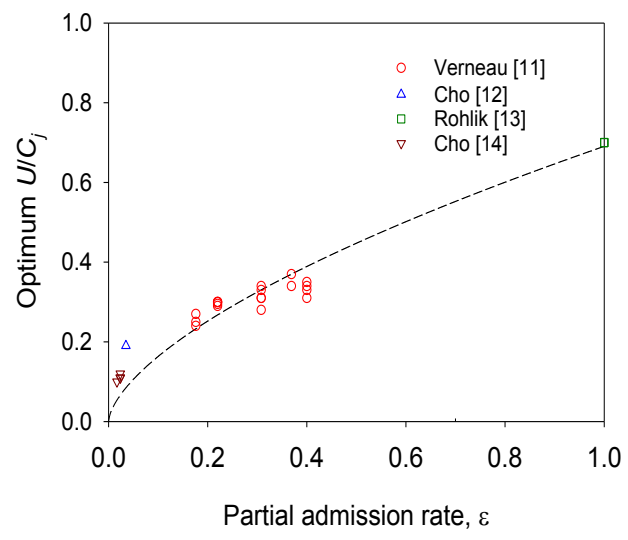

Fig. 3 Optimum velocity ratio in partial admission

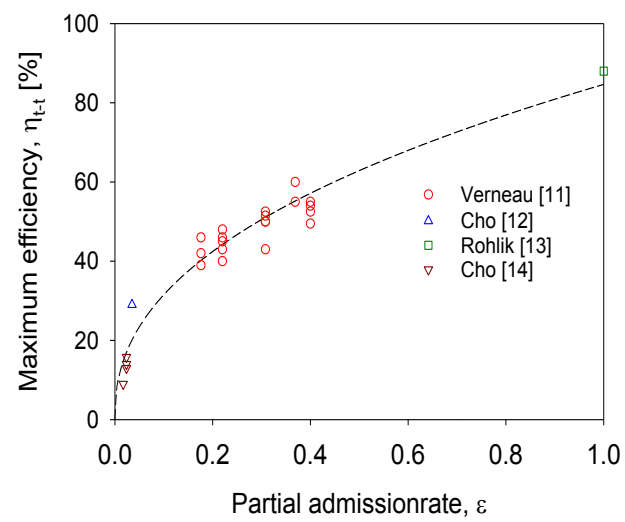

Fig. 4 Maximum efficiency in partial admission

The total pressure $\left(P_{t 3}\right)$ at the turbine exit is obtained as Eq. (5) using the isentropic process on the turbine

$$
\begin{aligned}
& h_{t 3 s}=h_{t 1}-\Delta h_{t} \\
& P_{t 3 s}=f\left(h_{t 3 s}, s_{t s 3}\right) \\
& P_{t 3}=P_{t 3 s}
\end{aligned}
$$

The total enthalpy $\left(h_{t 3}\right)$ at the turbine exit is obtained as Eq. (6) by applying the turbine efficiency, and the entropy is also calculated in the total pressure state.

$$
\begin{aligned}
& h_{t 3}=h_{t 1}-\frac{\Delta h_{t}}{\eta_{t-t}} \\
& s_{t 3}=f\left(h_{t 3}, P_{t 3}\right)
\end{aligned}
$$

The velocity $\left(C_{3}\right)$ at the turbine exit is decided by the shape of rotor, and this velocity determines the static enthalpy $\left(h_{3}\right)$ at turbine exit. The refrigerant which comes out from the turbine flows into the condenser. If the pressure loss on the circulation pipe is ignored and the velocity is converted to the pressure, the properties of the refrigerant at the saturated vapor state are determined by the pressure. After passing the condenser, this refrigerant is sub-cooled by $2^{\circ} \mathrm{C}$ from the saturated liquid state.

$$
\begin{aligned}
& P_{5}=P_{5 L}=P_{4} \\
& T_{5}=T_{5 L}-2^{\circ} C \\
& h_{5}, s_{5}=f\left(T_{5}, P_{5}\right)
\end{aligned}
$$

In order to operate the turbine, the refrigerant should be pressurized before entering the evaporator. The pressure after pumping should be equal to the pressure at the turbine inlet. The consuming power $\left(\Pi_{\text {pump }}\right)$ on the pump is evaluated with the pump efficiency $\left(\eta_{p u m p}\right)$ which was supposed to $85 \%$.

$$
\begin{aligned}
& h_{t 6 s}=f\left(P_{6}, s_{6}\right) \\
& \Pi_{\text {pump }}=\frac{h_{t 6 s}-h_{6}}{\eta_{\text {pump }}}
\end{aligned}
$$

The system efficiency can be determined from the input power including the pump power and the output power of the turbine

$$
\eta_{s y s}=\frac{\Pi-\Pi_{p u m p}}{h_{t 1}-h_{6}}
$$

\section{Turbine Configuration}

The turbine configuration for small scaled power is generally adopted the radial-type turbine. This radial-type turbine is usually not used in the supersonic flow because its flow area is reduced along the downstream. However, the radial-type turbine can be applied even the supersonic flow if it is operated in partial admission, since the flow area within the turbine is larger than the spouting area. The axial-type turbine is also able to apply for the small scaled power, but in this study, the radial type turbine was adopted because this type turbine could control more easily the mass flowrate.

When the turbine is operated in partial admission, the operating gas cannot fill the whole passage within the turbine. So, the impulse-type turbine is applied. The turbine output power is expressed using the velocities on the rotor fore and aft.

$$
\begin{aligned}
& \Delta h_{t}=C_{\theta 2} U_{2}-C_{\theta 3} U_{3} \\
& =\frac{1}{2}\left[\left(C_{2}^{2}-C_{3}^{2}\right)+\left(U_{2}^{2}-U_{3}^{2}\right)+\left(W_{3}^{2}-W_{2}^{2}\right)\right]
\end{aligned}
$$

The reaction of the impulse-type turbine can be expressed as Eq. (11).

$$
\begin{aligned}
& R=\frac{h_{2}-h_{3}}{h_{t 2}-h_{t 3}} \\
& =\frac{\frac{1}{2}\left(U_{2}^{2}-U_{3}^{2}\right)-\frac{1}{2}\left(W_{2}^{2}-W_{3}^{2}\right)}{h_{t 2}-h_{t 3}}
\end{aligned}
$$


In the axial-type turbine, the relative velocities at the inlet and exit are the same for the zero-reaction turbine. However, the radial-type turbine has smaller radius at the exit than that at the inlet. This causes the very small relative velocity at the exit. To avoid this problem, the radial-type turbine can be designed with some reaction.

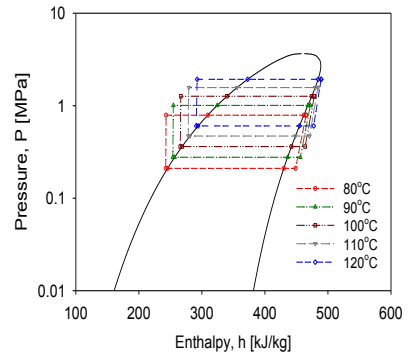

(a) P-h curve

Fig. 5 cycle of $30 \mathrm{~kW}$ class output power

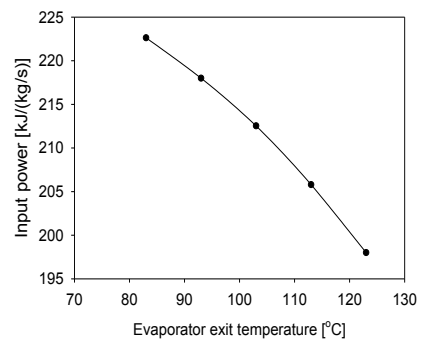

(a) input power

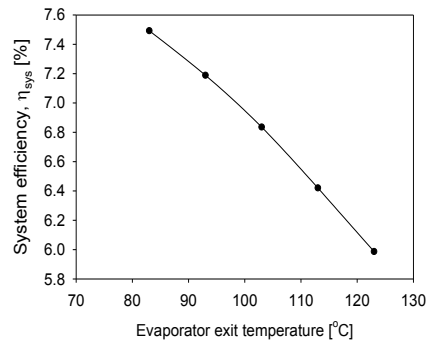

(c) turbine efficiency

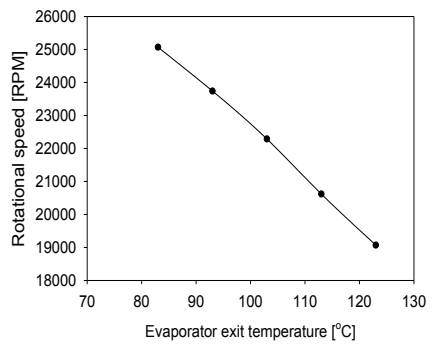

(e) rotational speed

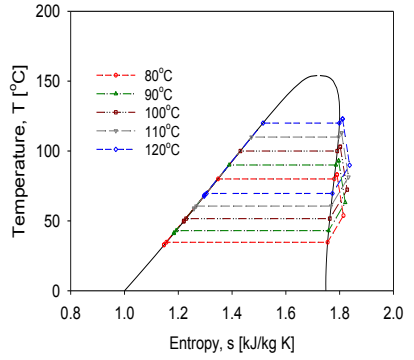

(b) T-s curve

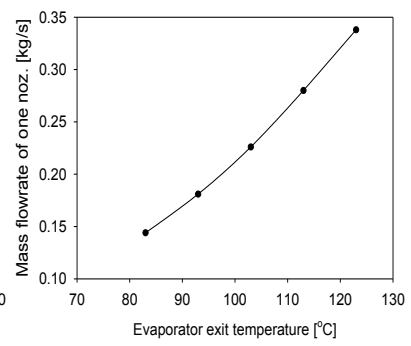

(b) mass flowrate on one nozzle

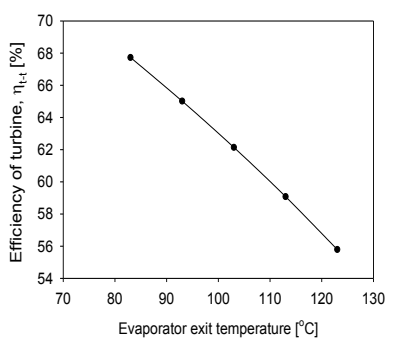

(d) system efficiency

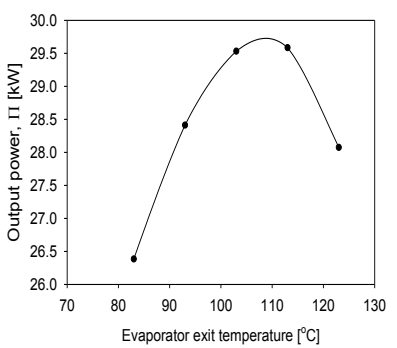

(f) output power

Fig. 6 variation of properties when the saturated vapor temperature on the evaporator is changed

\section{Cycle of $30 \mathrm{~kW}$ Class}

When many spouting nozzles are applied as stator, the turbine output power is changed like step function depending on the applied nozzle numbers at the same operating condition. For $30 \mathrm{~kW}$ class output power, the difference on the cycle was estimated for the various saturated vapor temperatures at the evaporator. This saturated vapor temperature was varied by $10^{\circ} \mathrm{C}$ from $80^{\circ} \mathrm{C}$ to $120^{\circ} \mathrm{C}$. The outer and inner diameters of the rotor were $100 \mathrm{~mm}$ and $60 \mathrm{~mm}$, respectively. The diameter at the nozzle exit was $8 \mathrm{~mm}$, and the spouting angle was $65^{\circ}$ based on the meridional direction.

Fig. 5 shows the P-h curve and T-s curve for the various saturated vapor temperatures. The increased temperature caused the pressure rising. For the same turbine output power, the pressure and temperature at the turbine exit were simultaneously increased for the increased inlet temperature. When the statured vapor temperature at the condenser inlet was decreased, it needed more work for condensing.

The differences on the cycle for the different saturated vapor temperature are shown in Fig. 6. When the saturated vapor temperature approached the critical temperature, the input power for evaporating was reduced. Therefore, the specific input power was decreased for the increased temperature, as shown in Fig. 6(a). The rising temperature increased the saturated pressure. Therefore, this increased pressure resulted in the increase of the mass flowrate on one nozzle, as shown in Fig. 6(b). Hence, the number of nozzle was reduced for the increased temperature. Only seven nozzles were applied for the $120^{\circ} \mathrm{C}$, Additional nozzle was needed according to each decrement of $10^{\circ} \mathrm{C}$. So, eleven nozzles were used for the $80^{\circ} \mathrm{C}$.

When the more nozzles were used, the partial admission rate was increased. This improved the turbine efficiency as shown in Fig. 6(c). When the temperature at the evaporator was increased, the input power was reduced. However, this caused the decrement of partial admission due to the reduced nozzle number, and affected the turbine efficiency. The system efficiency was reduced because the turbine efficiency had more effect although the specific input power was reduced, as shown in Fig. 6(d). This was the special characteristics on the partial admitted turbine compared to the full admitted turbine.

For the increased pressure at the turbine inlet, the spouting velocity was increased and the partial admission rate was decreased. Therefore, the optimum velocity ratio was reduced. This caused the reduction of the optimal rotational speed of the rotor, as shown in Fig. 6(e). Fig. 6(f) shows the output power on the turbine which is not the same because the applied nozzle numbers were different.

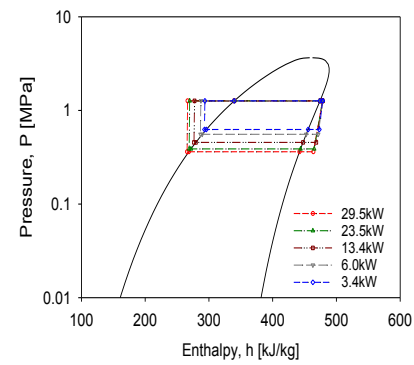

(a) P-h curve

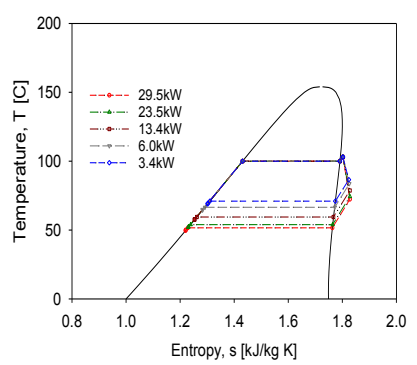

(b) T-s curve
Fig. 7 cycles for various output power

\section{Cycle of less $30 \mathrm{~kW}$}


In the section 4 , it showed that the low temperature at the turbine inlet had advantage on the system efficiency. However, the low temperature required more work on the condenser. This could be caused the trouble when the system was operated in hot summer. So, the turbine configuration was designed based on the saturated vapor temperature of $100^{\circ} \mathrm{C}$. The relative flow angles at inlet and at outlet were $35.3^{\circ}$ and $-54.4^{\circ}$ based on the meridional direction, respectively. The cycle analysis was conducted based on this turbine for the less $30 \mathrm{~kW}$ output power. Fig. 7 shows the P-h curve and the T-s curve for the different output power. The temperatures at the turbine inlet were the same because turbine operated at the same saturated vapor temperature, but the pressure and the temperature at the turbine exit were varied. For the increased turbine power, the pressure and the temperature at the turbine exit were reduced. For the lower turbine power, the work on the condenser was reduced and the temperature gap between on the condenser and the on the atmosphere was increased.

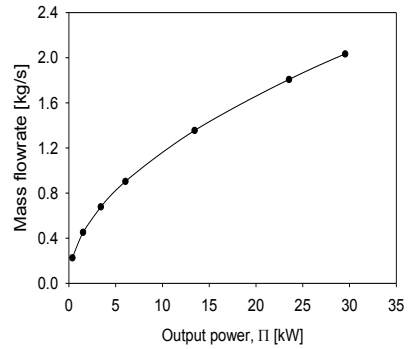

(a) mass flowrate

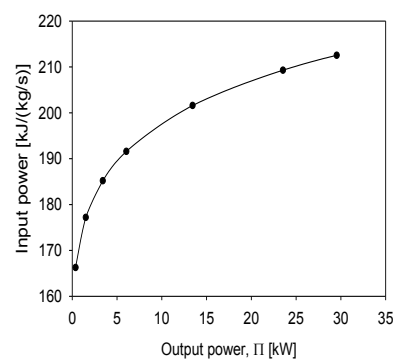

(c) input power

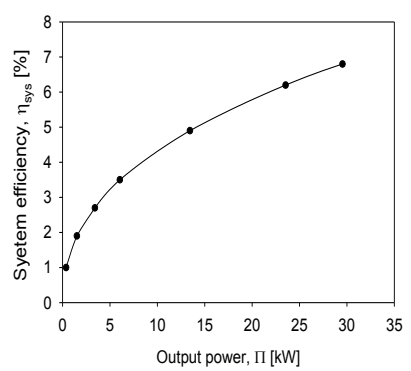

(e) turbine efficiency

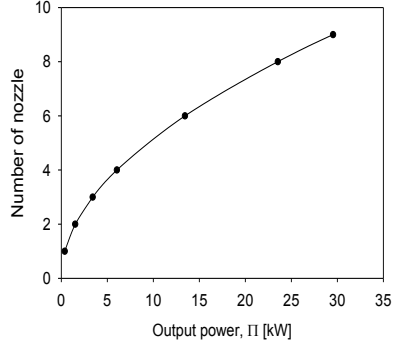

(b) number of nozzle

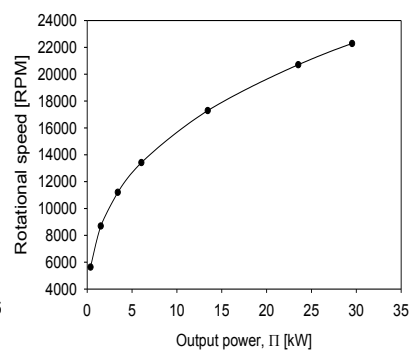

(d) rotational speed

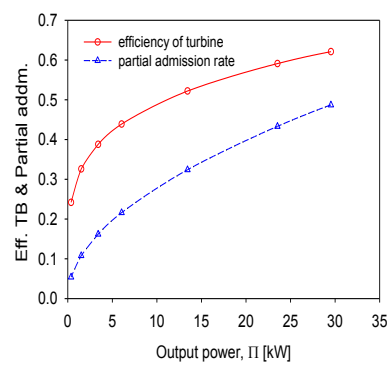

(f) system efficiency

Fig. 8 variation of properties when the turbine output power is changed

Fig. 8 shows the variation of properties on the cycle for the different output power. For the reduced output power, the mass flowrate was reduced, as shown in Fig. 8(a). In order to reduce the mass flowrate, the number of nozzles should be reduced, as shown in Fig. 8(b). For the reduced turbine power, the temperature at the turbine exit was increased. So, the specific input power was reduced, as shown in Fig. 8(c). In addition, the reduced turbine power caused the reduction of the partial admission rate. So, the optimum velocity ratio was decreased. Although the increased pressure at the turbine exit reduced the spouting velocity, the reduction rate of the optimum velocity ratio was larger. Therefore, the optimum velocity ratio was decreased, as shown in Fig. 8(d). Fig. 8(e) shows the reduction of the partial admission and the turbine efficiency for the decreasing turbine output power due to the reduction of nozzle number. Although the input power on the evaporator was reduced for the reduced turbine power, the system efficiency was decreased because the turbine efficiency was decreased, as shown in Fig. 8(f).

\section{Cycle of $5 \mathrm{~kW}$ Class}

In section 5, it showed that the temperature at the turbine exit was increased for the lower turbine output power when the temperature at the turbine inlet was the same. The lower temperature at the turbine inlet could increase the system efficiency if the temperature at the turbine exit maintained certain level for condensing. Therefore, for obtaining the $5 \mathrm{~kW}$ output power using the same turbine and nozzle designed for $30 \mathrm{~kW}$ output power, the temperature at the turbine inlet was varied to find the difference on the cycle. The number of applied nozzle was three. The same turbine efficiency of $39 \%$ was applied because its partial admission rate was $16.2 \%$.

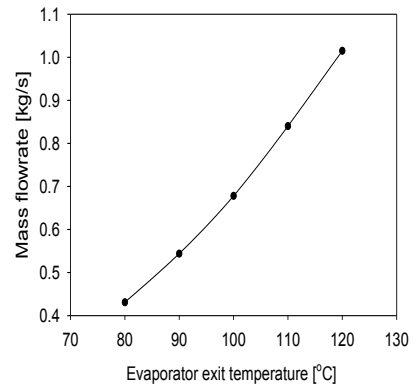

(a) mass flowrate

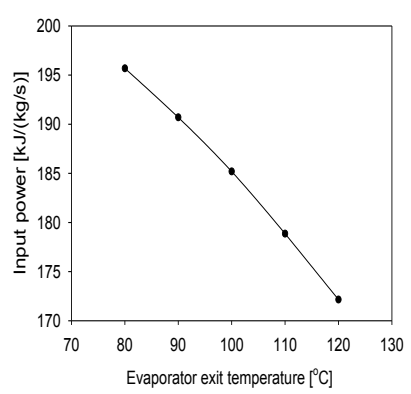

(c) input power

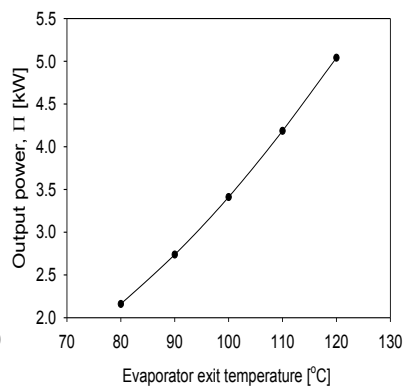

(b) output power

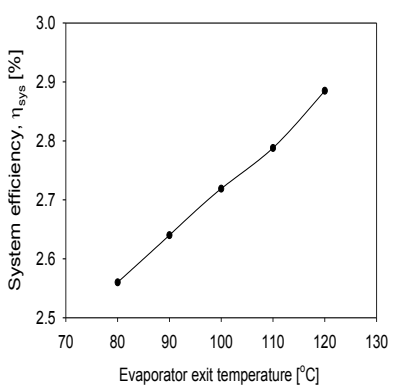

(d) system efficiency
Fig. 9 variation of properties when the saturated vapor temperature on the evaporator is changed with the same nozzle number

For the same number of nozzles, the pressure was increased if the temperature at the evaporator was increased. This increased pressure caused to increase the mass flowrate on the nozzle. Fig. 9(a) shows the increased mass flowrate according to the increased temperature. This increased mass flowrate affected directly the turbine 
output power. As shown in Fig. 9(b), the turbine output power was increased for the increased temperature.

When the temperature at the evaporator was increased, the specific input power at the evaporator was reduced, as shown in Fig, 9(c). However, in the system, the mass flowrate was increased, so the input power at the evaporator was increased. This increased mass flowrate caused the increased turbine output power. Since the increasing rate of turbine power was larger than that of input power at the evaporator, the efficiency of the system was increased, as shown in Fig. 9(d).

It was already shown in section 4 that the system efficiency could improve by reducing the temperature at the turbine exit if this temperature kept up a certain level. In order to obtain the same output power, more nozzles could be applied because the mass flowrate was reduced for the lower temperature at turbine exit. For the three nozzles, the temperature at the turbine exit was maintained to $54.4^{\circ} \mathrm{C}$ when the temperature at the evaporator was $80^{\circ} \mathrm{C}$. At this condition, one more nozzle was applied. Then, the system efficiency was increased to $3.3 \%$ from $2.56 \%$. The turbine output power increased by $77 \%$, as shown in Table 1. This system efficiency of $3.3 \%$ was better than that obtained when the temperature at the evaporator was increased to $120^{\circ} \mathrm{C}$. For applying four nozzles, the temperature at the turbine exit was slightly decreased due to the increased turbine power.

Table 1 Operating conditions with 4 nozzles

\begin{tabular}{|l|c|l|}
\hline Contents & Specification & Remarks \\
\hline Mass flowrate & $0.575 \mathrm{~kg} / \mathrm{sec}$ & 4 nozzles \\
\hline Partial admission rate & $16.4 \%$ & \\
\hline Output power & $3.83 \mathrm{~kW}$ & \\
\hline Rotational speed & $13,300 \mathrm{RPM}$ & \\
\hline Turbine efficiency & $43.9 \%$ & \\
\hline System efficiency & $3.3 \%$ & \\
\hline
\end{tabular}

\section{Conclusion}

The cycle analysis of ORC was conducted with R245fa for obtaining small scaled output power from the low temperature heat source. For the various output power, off-design point analysis was studied. When the turbine output power was small scale class, the turbine could not work at full admission. The turbine output was much dependent on the turbine efficiency which was directly related with the partial admission rate. Therefore, if the temperature at the turbine exit was not too low to make a trouble for condensing, it was better reducing the temperature at the evaporator and increasing the partial admission rate to improve the system efficiency.

\section{Acknowledgement}

The authors would like to acknowledge the financial support offered by grant No. RTI04-01-03 from the Regional Technology Innovation Program of the Ministry of Commerce, Industry and Energy (MOCIE) of the Korean government, and the hybrid wind power system development project supported by Honam regional Goverement.

\section{References}

[1] C. E. Cong, "Solar Thermal Organic Rankine Cycle as a Renewable Energy Option," Jurnal Mekanikal, (2005), Dec., No. 20, pp. 68-77.

[2] B. T. Liu, K. H. Chie and C. H Wang, "Effect of Working Fluids on Organic Rankine Cycle for Waste Heat Recovery," Energy, (2004), Vol. 29, pp. 1207-1217.

[3] T. C Hung, T. Y. Shai and S. K. Wang, "A Review of Organic Rankine Cycles for the Recovery of Low-Grade Waste Heat," Energy, (1997), Vol. 22, No. 7 pp. 661-667.

[4] T. C. Hung, S. K. Wang, C. H. Kuo, B. S. Pei and K. F. Tsai, "A Study of Organic Working Fluids on System Efficiency of an ORC Using Low-Grade Energy Sources," Energy, (2010), Vol. 35, pp. 1403-1411.

[5] P. Gang, L. Jing and J. Jie, "Analysis of Low Temperature Solar Thermal Electric Generation Using Regenerative Organic Rankine Cycle," Applied Thermal Engineering, (2010), Vol. 30, pp. 998-1004.

[6] T. Yamamoto, T. Furuhata, N. Arai and K. Mori, "Design and Testing of the Organic Rankine Cycle," Energy, (2001), Vol. 26, pp. 239-251.

[7] P. Welch and P. Boyle, "New Turbines to Enable Efficient Geothermal Power Plants," GRC Transactions, (2009), Vol. 33, pp. 765-772.

[8] S. H. Kang, "Design and Experimental Study of ORC and Radial Turbine using R245fa Working Fluid," Energy, (2012), Vol. 41, pp.514-524.

[9] S. Declaye, S. Quoilin, and V. Lemort, "Design of Experimental Investigation of a Scroll Scale Organic Rankine Cycle Using a Scroll Expander," Int. Refrigeration and Air Conditioning Conference at Purdue, (2010), 2512, pp. 1-7.

[10] NIST, "Reference Fluid Thermodynamics and Transport Properties," Refprop version8.0, ( 2007).

[11] A. Verneau, "Supersonic Turbines for Organic Fluid Rankine Cycles from $3 \mathrm{~kW}$ to $1300 \mathrm{~kW}$," VKI Lecture Series 1987-09, (1987).

[12] S. Y. Cho, C. H. Cho and C. Kim, "Performance Prediction on a Partially Admitted Small Axial-type Turbine," JSME international J. Series B, (2006), Vol. 49, No. 4, pp. 12901297.

[13] H. E. Rohlik, "Radial-Inflow turbines," Turbine Design and Application, (1973), Vol. 2, NASA SP-290.

[14] S. Y. Cho, C. H. Cho and C. Kim, "Performance Characteristics of a Turbo Expander Substituted for Expansion Valve on Air-conditioner," Experimental Thermal and Fluid Science, (2008), Vol. 32, pp. 1655-1665. 